\title{
Gas Evolution during Mechanical Milling of Hematite-Graphite Mixture
}

\author{
Yoshiaki KASHIWAYA, Hiroshi SUZUKI' and Kuniyoshi ISHII \\ Graduate School of Engineering, Hokkaido University, Sapporo, 060-8628 Japan. E-mail: Yoshiaki@eng.hokudai.ac.jp \\ 1) Student of Graduate School of Engineering, Hokkaido University, Sapporo 060-8628 Japan.
}

(Received on May 24, 2004; accepted in final form on July 28, 2004)

\begin{abstract}
In previous studies, the reactivity of hematite-graphite mixture obtained by the mechanical milling was investigated. The rate of reaction has remarkably increased and the starting temperature of reaction decreased with the milling time. Understanding the phenomena and its mechanism occurring in the milling would contribute to develop the new feeding material for ironmaking process.

In this study, milling of hematite and graphite mixture was carried out with the same procedure. Gas analysis by QMS was performed to clarify the evolved gas during milling qualitatively and quantitatively.

Gas evolution from graphite was mainly $\mathrm{CO}$ gas. $\mathrm{CO}_{2}$ gas also evolved in the early stage of milling. These gases would be related to the adsorbed gases before milling. When the sample exposed to air in the course of milling, much gas adsorbed on the surface of milled graphite, which increased with the increasing milling time.

When the hematite and graphite mixture was milled under argon atmosphere, mainly CO gas evolved owing to the reduction reaction.

From these results of gas analysis, the mechanisms for the gas evolution during the milling were proposed.
\end{abstract}

KEY WORDS: gas evolution; composite pellet; mechanical milling; ball milling; reduction; carbothermic reduction.

\section{Introduction}

In previous studies, ${ }^{1,2)}$ the authors have investigated the reactivity of hematite-graphite mixture obtained by the mechanical milling. The rate of reaction has remarkably increased and the starting temperature of reaction decreased in accordance with the milling time. Understanding the phenomena and its mechanism occurring in the milling would contribute to develop the new feeding material for ironmaking process.

A number of the affecting factors on the reactivity of the mechanically milled mixture existed. ${ }^{1)}$ Furthermore, as the factors are interacting each other, the apparent results were complicated extremely. For example, since the grindability of the sample will strongly affect on the property of the powder obtained, the difference of the crystalline size and its distribution in addition to the hardness of single crystal will result in the variety of the reactivity of the milled sample. In addition, the interaction between the crystal characteristics (or strength) of iron oxides (hematite, magnetite and wustite) and the milling energy (200 rpm or $500 \mathrm{rpm}$ with 10 or 20 balls) caused the quite different results such as the gas evolution related to the reduction reaction and the formation of the active complex having extremely high reaction rate.

To understand the reaction behavior obtained from mechanical milling, it is very important to clarify the phenom- ena occurring in the course of milling. It can be easily imagine the importance of the impact energy and the frequency, so that the rotation speed, the weight of ball and the number of ball were also important factors to control the milling effect on the powder.

In previous paper, ${ }^{2)}$ we have made clear the phenomena occurring in the course of milling except gas evolution: 1) the characteristics of nano-reactor introduced by mechanical milling was elucidated through the observations of FESEM and TEM, 2) the crystal size degradation was measured by X-ray diffraction, and 3) the formation of the reduction product during the milling was confirmed.

In this study, the gas evolution during the milling was investigated and the several kinds of mechanism were proposed, because the gas evolution was related to both the adsorbed gases and the reduction reaction.

\section{Experimental}

Figure 1 shows the conventional milling vessel and the atmosphere controlled milling one. The packing is usually made of Teflon which is relatively low gas tightness. In present study, we carried out the milling of the graphite and the mixture of hematite and graphite, which became high reactivity with increasing milling time. The high active sample would soon react with the oxygen leaked from the atmosphere, if the gas tightness was lower. Then, we have 


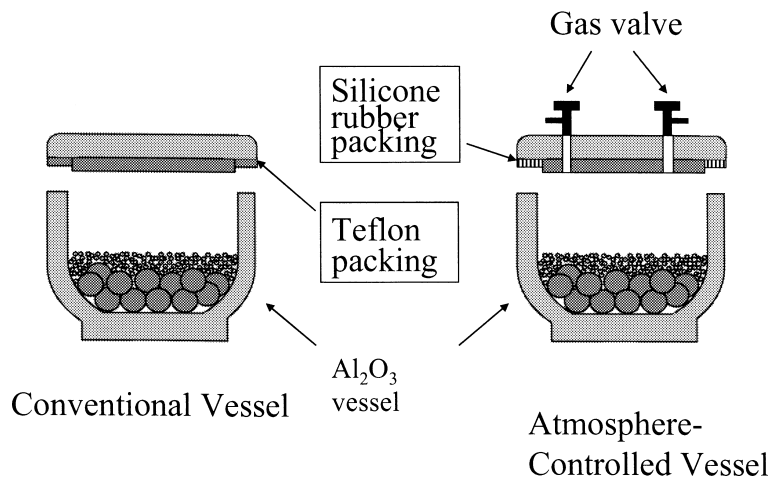

Fig. 1. Comparison of the milling vessel between the conventional and the atmosphere controlled one.

developed the packing made of a silicone rubber, which could carry out the milling under a high gas tight condition. However, it should take care of the dangerous situation that is a explosion or a rapid combustion in order to a high reactivity, when the cap of vessel was opened after milling. Even if the drastic phenomena did not occur, a large amount of the gas adsorption and/or chemisorption would occur, so that the reactivity of milling sample might change significantly. It means that the opening the cap after milling under an air atmosphere is not only dangerous but also important to obtain the stable result of reactivity measurement. Normally, we opened the vessel in a draft chamber for a safety and quickly collected a small amount of sample, then continued the milling. It was considered that the gases evolved during milling might adsorbed on the surface of milled sample at this procedure. In some experiment for confirming the gas adsorption in this procedure, the vessel was opened under an argon atmosphere using the glove box for the sampling. The glove box was evacuated and substituted with an argon with the flow rate of $10000 \mathrm{~cm}^{3} / \mathrm{min}$ (STP) .

Figure 2 shows the mechanism of planetary milling device. The milling vessel was located on the turntable which enabled the two different movements of the revolution and the rotation, simultaneously. Using these movements, the grindability can increase effectively. Figure 3 shows the gas analysis system for the quantifying the evolved gas during the milling. The vessel after milling was set onto the gas analysis system. Before gas analysis, the gas remained in the tubing system was evacuated and substituted with argon. Then, the constant flowrate of $500 \mathrm{~cm}^{3} / \mathrm{min}$ of argon was flowed through the by-pass, when the valves of the vessel were closed. The residual oxygen in the argon gas was monitored by QMS (Quadrupole Mass Spectrometer). After confirming the residual oxygen in argon decreased to the original level $(<100 \mathrm{ppm})$, the valves on the cap were opened and the evolved gases $\left(\mathrm{CO}, \mathrm{CO}_{2}, \mathrm{O}_{2}\right.$ and $\left.\mathrm{H}_{2}, \mathrm{H}_{2} \mathrm{O}\right)$ during the milling were analyzed.

Experimental conditions of milling were shown in Table 1. In present experiment, main purpose is to detect the gas produced by the reduction reaction, however, the sample, especially graphite, adsorb and/or chemisorb a variety of gases originally. It was considered that those gases would be released during the milling. To separate the gas from the reduction reaction, only graphite was milled and the evolved gas was analyzed to clarify the originally adsorbed

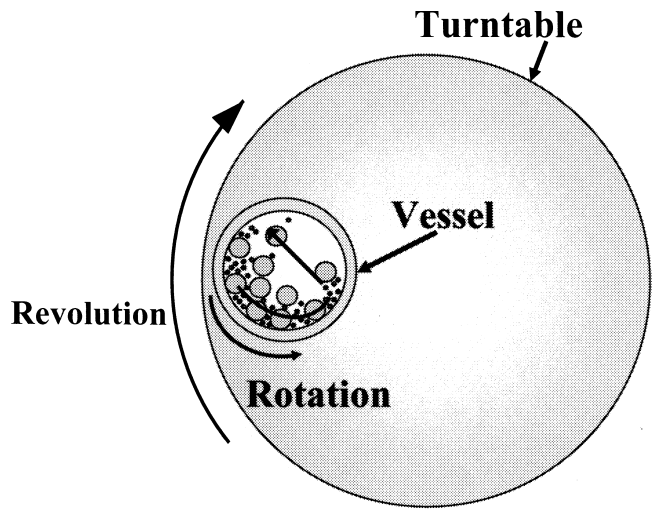

Fig. 2. Illustration of movements of the planetary ball mill.

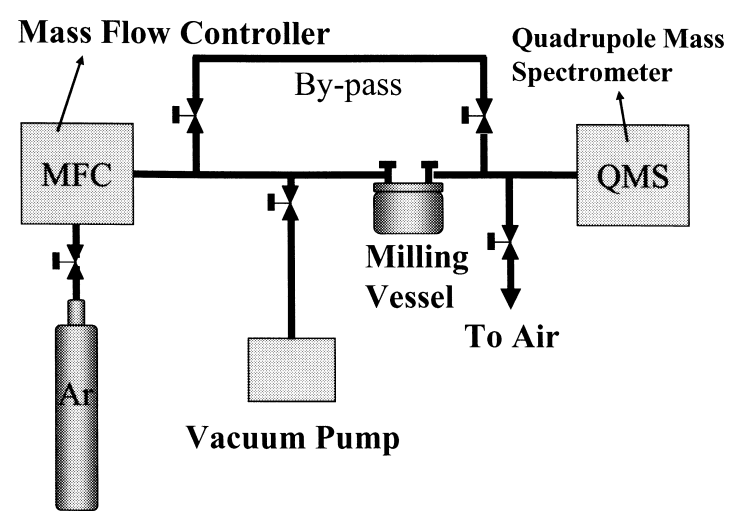

Fig. 3. Schematics of experimental apparatus for the gas analysis in the vessel of milling.

Table 1. Experimental conditions.

\begin{tabular}{|c|c|c|c|c|c|}
\hline Notation & Number of ball & Sample(s) & $\mathrm{C}: 0$ & $\begin{array}{c}\text { Rotation } \\
\text { rate }\end{array}$ & Atmosphere \\
\hline Graphite & $\begin{array}{c}10 \\
(20 \phi)\end{array}$ & Graphite $55.7 \mathrm{~g}$ & $1.0: 0.0$ & $200 \mathrm{rpm}$ & $\begin{array}{c}\text { Argon or } \\
\text { Air }\end{array}$ \\
\hline Mixture*10 & $\begin{array}{c}10 \\
(20 \phi)\end{array}$ & $\begin{array}{c}\text { Graphite,14.3g } \\
\text { Hematite,50.0g }\end{array}$ & $1.3: 1.0$ & $200 \mathrm{rpm}$ & $\begin{array}{c}\text { Argon or } \\
\text { Air }\end{array}$ \\
\hline Mixture*20 & $\begin{array}{c}20 \\
(20 \phi)\end{array}$ & $\begin{array}{c}\text { Graphite,14.3g } \\
\text { Hematite,50.0g }\end{array}$ & $1.3: 1.0$ & $200 \mathrm{rpm}$ & $\begin{array}{c}\text { Argon or } \\
\text { Air }\end{array}$ \\
\hline
\end{tabular}

gases.

The weight of graphite sample was $55.7 \mathrm{~g}$ which corresponded to the required volume to conduct the milling for $500 \mathrm{~cm}^{3}$ vessel. In the case of hematite and graphite mixture, the weight of hematite was $50.0 \mathrm{~g}$ and the graphite was $14.3 \mathrm{~g}$, which were almost the same volume against only the graphite milling and the mole ratio of oxygen in hematite to carbon was $1.3: 1.0$. The rotation rate was constant and $200 \mathrm{rpm}$ for all experiment, and the milling energy was changed by the number of ball, one was 10 and the other was 20 .

\section{Results and Discussions}

\subsection{Gas Evolution under an Argon Atmosphere}

As mentioned above, the graphite sample originally adsorbed some gases which increased with the increasing milling time, when it was exposed to an air atmosphere. The graphite sample was milled at $1 \mathrm{~h}, 24 \mathrm{~h}, 48 \mathrm{~h}$ and $72 \mathrm{~h}$, respectively, and a small amount of graphite sample (about $40 \mathrm{mg}$ ) was collected for the measurement of reactivity using TG-DTA, whose results will be published in same journal. $^{2)}$ At this procedure, the graphite samples were ex- 


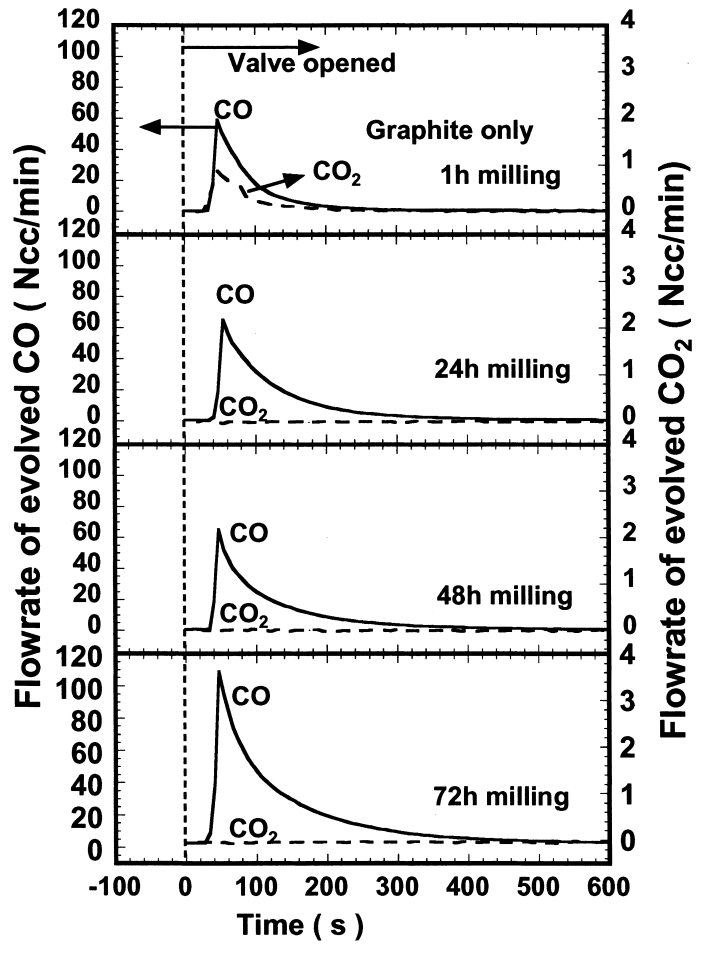

Fig. 4. Comparison of the results of gas analysis among different milling time. (Graphite only)

posed to air for a short time in order to collect. Figure 4 shows the comparison of the results of gas analysis for different milling time. When the valves on the cap of the vessel were opened, $\mathrm{CO}$ and $\mathrm{CO}_{2}$ increased from about $40 \mathrm{~s}$ $\left(\mathrm{O}_{2}, \mathrm{H}_{2}\right.$ and $\mathrm{H}_{2} \mathrm{O}$ were also measure at the same time, but the amount of gases were almost negligible). At $1 \mathrm{~h}$ milling, $\mathrm{CO}_{2}$ content was relatively large, although the amount was small comparing to $\mathrm{CO}$ gas (the axis of $\mathrm{CO}_{2}$ is right hand side). From $24 \mathrm{~h}$ milling, $\mathrm{CO}_{2}$ was not detected, while the amount of $\mathrm{CO}$ was almost the same as those for $24 \mathrm{~h}$ and $48 \mathrm{~h}$. The detected gas might be the one adsorbed during the handling of sample for the collection. When the milling time increased to $72 \mathrm{~h}$, the $\mathrm{CO}$ gas evolution became large as shown in Fig. 4. This result might relate to the reactivity of the milled carbon. It was considered that the evolved gas at $1 \mathrm{~h}$ was the adsorbed gas originally and the reason of $\mathrm{CO}_{2}$ evolution was the difference of state of oxygen adsorption. From $24 \mathrm{~h}$, the gases would be the one adsorbed during the sampling before the starting of subsequent milling. So that it can be concluded that the large amount of $\mathrm{CO}$ evolution at $72 \mathrm{~h}$ milling meant the high reactivity of carbon after $48 \mathrm{~h}$ milling. To certify this mechanism, the vessel was opened in the glove box under an argon atmosphere. Even $100 \mathrm{~h}$ milling, there was no gas evolution observed. From this result, the best way for reactivity measurement after milling would be carried out everything under an inert atmosphere, especially for the handling of sample from the milling vessel to the crucible of TG-DTA. However, as it was impossible, the amount of adsorbed gas was evaluated from the difference between the only graphite and the hematite-graphite mixture. Then, the inherent value of reduction reaction during milling of the mixture was determined.

Figure 5 shows the results of gas analysis after $48 \mathrm{~h}$ and $72 \mathrm{~h}$ for the mixture of graphite and hematite, that the

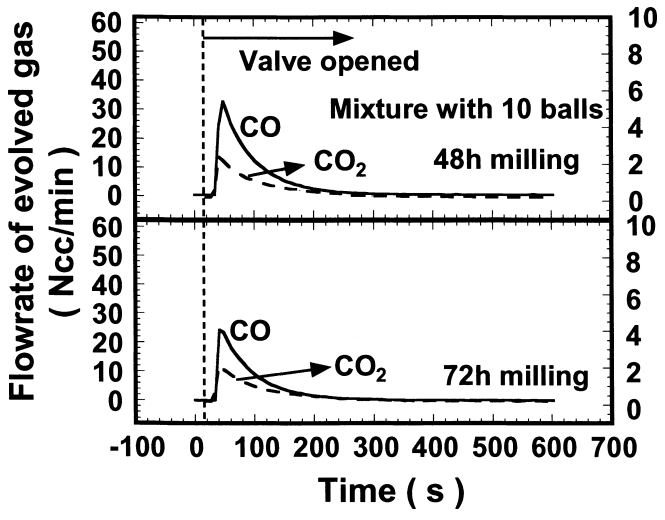

Fig. 5. Comparison of the results of gas analysis among different milling time. (Mixture of hematite and graphite, 10 balls)

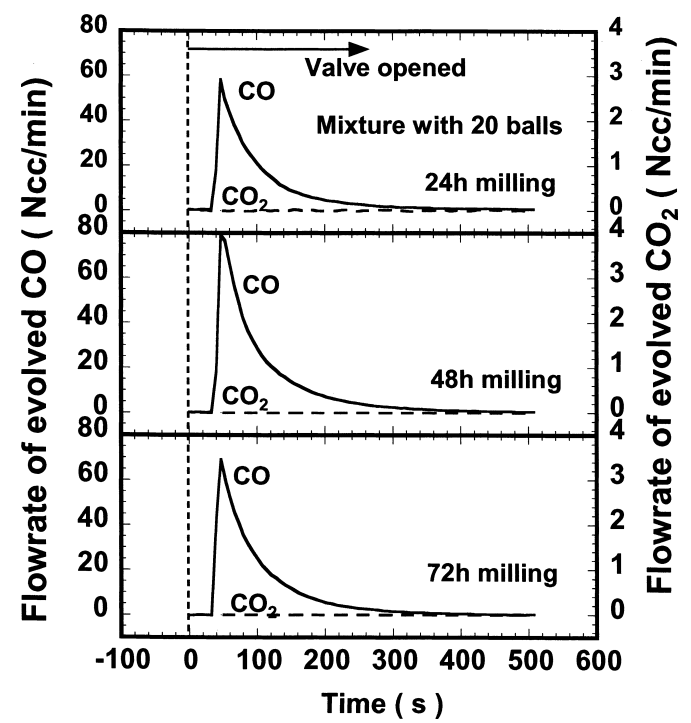

Fig. 6. Comparison of the results of gas analysis among different milling time. (Mixture of hematite and graphite, 20 balls)

milling was carried out with 10 alumina balls $(20 \mathrm{~mm} \phi$ in diameter). It was found that every milling experiments had similar gas evolution in which both of $\mathrm{CO}$ and $\mathrm{CO}_{2}$ generated during milling (in Fig.5, some experiments $(1 \mathrm{~h}$ and $24 \mathrm{~h}$ ) were not presented, because the calibration of QMS for the quantitative analysis was failed. However, the $\mathrm{CO}_{2}$ evolution could be observed clearly). In comparison with 10 balls milling, there was little evolution of $\mathrm{CO}_{2}$, when the millings were carried out with 20 balls as shown in Fig. 6. The difference between 10 and 20 balls was to be a difference of energy on the milling. As the 20 balls milling should have a higher milling energy, the mechanism of gas evolution might change with the milling energy. One possibility of gas evolution mechanism were presented in later section.

Total volume of evolved gas per a unit mass of graphite was evaluated by the integration of the measured gas evolution curve. The results are shown in Fig. 7. It was found that the total gas evolved from mixture was larger than that from only the graphite, which meant the existence of reduction reaction. Moreover, since the gas volume in the milling of 20 balls was largest, it would be important to apply the larger energy of milling for the enhancement of the reduction. The net gas evolution corresponding to the reduction would be the difference from the gas evolution of the 


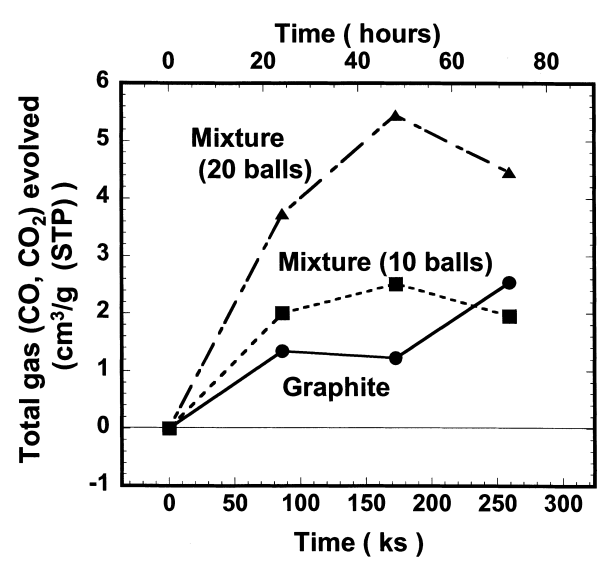

Fig. 7. Total gas volume evolved during the milling.

graphite only. However, in longer milling sample at $72 \mathrm{~h}$, the amount of evolved gas showed the opposite behavior between the graphite only and the mixture. As mentioned above, graphite should be active in accordance with the milling time, then, the amount of gas evolution would increase. On the other hand, the milling of hematite and graphite mixture would proceed the reduction reaction, especially in the longer milling time. This situation means that the active carbon already reacts with the hematite. Even if the reduction reaction could not proceed completely (until the $\mathrm{CO}$ gas evolution), the active complex might generate in the course of the reaction as shown in Eq. (1)

$$
3 \mathrm{Fe}_{2} \mathrm{O}_{3}+\mathrm{C} \stackrel{i 1}{\rightarrow}\left(2 \mathrm{~F}_{3} \mathrm{O}_{4} \cdot \mathrm{CO}\right) \stackrel{i 4}{\rightarrow} 2 \mathrm{Fe}_{3} \mathrm{O}_{4}+\mathrm{CO}
$$

The theoretical approach and validity of Eq. (1) has been confirmed through the kinetic analysis based on the transition state theory. ${ }^{3-5)}$ The extremely active state of the product of milling was confirmed through the values of Enthalpy $\Delta H^{*}$ and Entropy $\Delta S^{*}$ of activation. ${ }^{3)}$ If the active complex $\left(2 \mathrm{Fe}_{2} \mathrm{O}_{4} \cdot \mathrm{CO}\right)^{*}$ increased in the longer milling time, the evolved gas during the milling might decrease but the reactivity of the milled sample increase. Furthermore, although the reduction degree from hematite to magnetite ( $\mathrm{H}-\mathrm{M}$ reduction) is $11 \%$, the one calculated from the total gas evolution was about $4 \%$ as maximum. This result means that the amount of $\mathrm{CO}$ evolution might limited in order to the interaction between the crystal characteristics (or strength) of iron oxides (hematite, magnetite and wustite) and the milling energy (200rpm with 20 balls), because the gas evolution extremely increased in the higher milling energy (e.g. $500 \mathrm{rpm})$, which will be published in near future.

\subsection{Gas Evolution under an Air Atmosphere}

We have also carried out the milling experiment under an air atmosphere in which the oxygen was supplied continuously. It was found that the remained carbon decreased. Although the gas analysis by QMS could not distinguish $\mathrm{CO}$ gas from a nitrogen, the total volume of gas remained in the vessel was obviously increased. A figure was not presented here, as it was impossible to conduct a quantitative discussion. Since there was no $\mathrm{CO}_{2}$ gas detected in all experimental conditions, it was considered that the evolved gas under an air atmosphere was CO gas only.

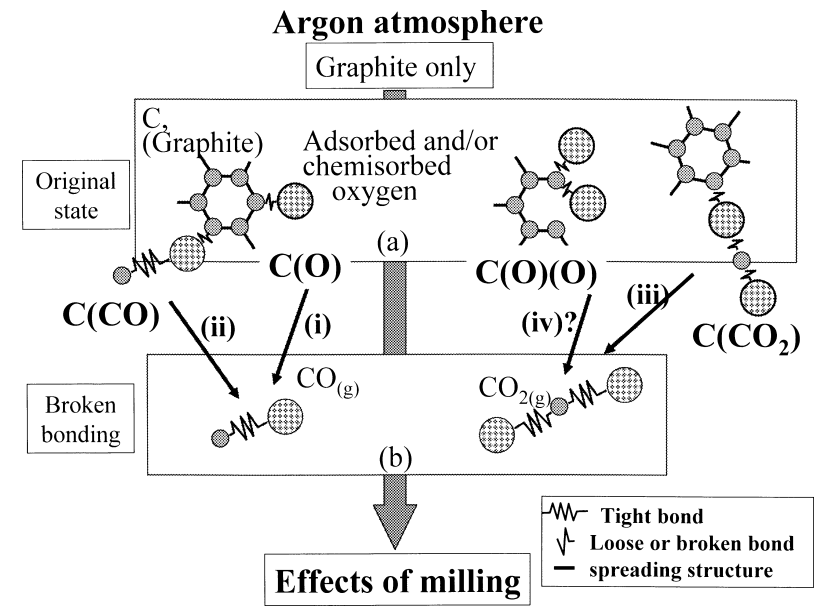

Fig. 8. Mechanism of gas evolution during the milling of the graphite only under argon atmosphere.

\subsection{Mechanisms of Gas Evolution}

From these results, the several mechanisms of gas evolution were considered as follows.

Figure 8 shows the possible mechanism of gas evolution from graphite under an argon atmosphere during the milling. As shown in Fig. 4, $\mathrm{CO}_{2}$ gas was detected only in $1 \mathrm{~h}$ milling. $\mathrm{CO}$ was mainly detected in the longer milling time. The state of adsorbed gas species on the active carbon having dangling bond would be considered as follows. ${ }^{6-9)}$

(i) adsorbed $\mathrm{O}: \quad \mathrm{C}(\mathrm{O}) \rightarrow \mathrm{CO}(\mathrm{g})$

(ii) adsorbed $\mathrm{CO}: \quad \mathrm{C}(\mathrm{CO}) \rightarrow \mathrm{CO}(\mathrm{g})$

(iii) adsorbed $\mathrm{CO}_{2}: \mathrm{C}\left(\mathrm{CO}_{2}\right) \rightarrow \mathrm{CO}_{2}(\mathrm{~g})$

At the beginning of milling, most of adsorbed gas would be expressed as $\mathrm{C}(\mathrm{CO})$ and $\mathrm{C}\left(\mathrm{CO}_{2}\right)$, which are $\mathrm{CO}$ and $\mathrm{CO}_{2}$ gas adsorbed on the carbon having dangling bond. In the case of first $1 \mathrm{~h}$ milling, relatively large amount of $\mathrm{CO}_{2}$ was observed as shown in Fig. 4. The reactions will be expressed by (ii) and (iii).

On the other hand, the crystal structure of graphite would be broken during milling, in which the same situation as the gasification reaction $\left(\mathrm{C}+\mathrm{CO}_{2} \rightarrow 2 \mathrm{CO}\right)$ would occur, that the carbon atom in the solid phase moved to the gas phase ((i) in Fig. 8). In such a case, reaction (i) would be dominant. It might be difficult to generate $\mathrm{CO}_{2}$ in this explanation. One possibility can be expressed as follow.

(iv) double adsorption of oxygen $\mathrm{O}: \mathrm{C}(\mathrm{O})(\mathrm{O}) \rightarrow \mathrm{CO}_{2}(\mathrm{~g})$ This mechanism was presented in the water gas reaction. ${ }^{8,9)}$ It would be unlikely to occur in this case. So that it would be the cause that the evolution of $\mathrm{CO}_{2}$ was limited in the early stage of milling for the graphite only.

Figure 9 shows the mechanism of gas evolution in the hematite and graphite mixture under argon atmosphere. When the bonding of iron atom and oxygen atom in the hematite structure was broken, it was formed a dangling bond both in the oxygen and iron atom on the broken surface, a carbon atom in the graphite structure would have connection with the oxygen and finally, it could make a CO gas as shown in Fig. 9(c). The reaction should have a step of a active complex as shown in Eq. (1), which caused to the high rate of reduction between the iron oxide and the graphite. ${ }^{1,3)}$ In comparison of Fig. 5 with Fig. 6, the lower milling energy could produce the lager amount of $\mathrm{CO}_{2}$. 


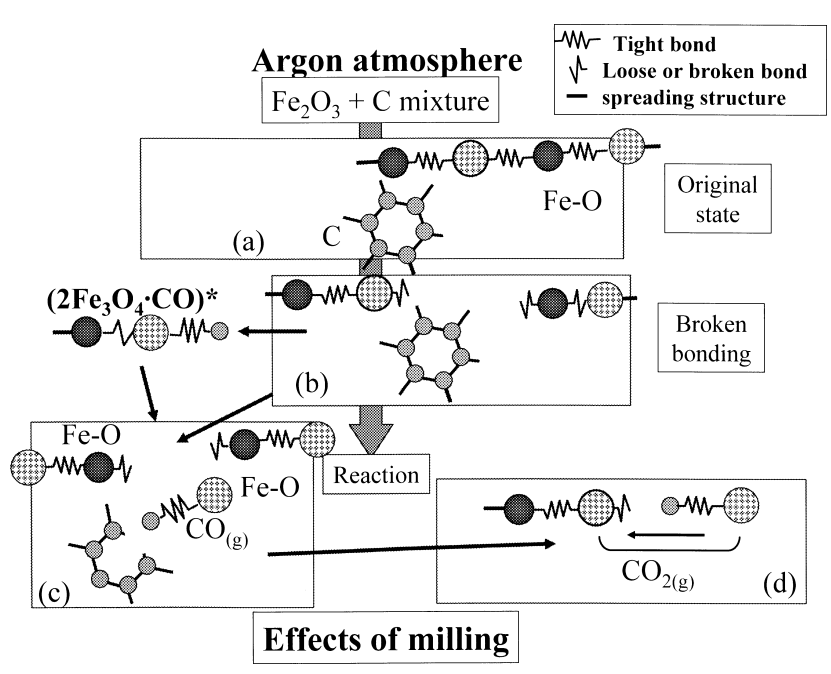

Fig. 9. Mechanism of gas evolution during the milling of the mixture under argon atmosphere.

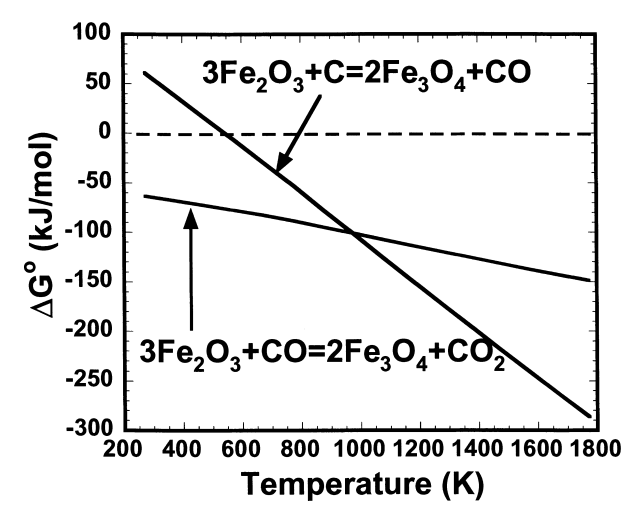

Fig. 10. Gibbs free energy of the reduction reactions.

That is, the path from (c) to (d) in Fig. 9 will be predominant in the milling with 10 balls, while in 20 balls milling, the rate from (b) to (c) would be very high. Furthermore, as the local temperature resulted from high energy milling might increase, the reaction (2) might be thermodynamically dominant than reaction (3) as shown in Fig. 10.

$$
\begin{gathered}
3 \mathrm{Fe}_{2} \mathrm{O}_{3}+\mathrm{C}=2 \mathrm{Fe}_{3} \mathrm{O}_{4}+\mathrm{CO} \\
3 \mathrm{Fe}_{2} \mathrm{O}_{3}+\mathrm{CO}=2 \mathrm{Fe}_{3} \mathrm{O}_{4}+\mathrm{CO}_{2}
\end{gathered}
$$

In Fig. 11, some possible mechanisms might be occurring under an air atmosphere both for hematite-graphite mixture and for graphite only. The variations of crystalline size in the hematite and the graphite during milling were estimated by the XRD in previous study. ${ }^{2)}$ In the case of milling of the mixture under an air atmosphere, there was no decrease of crystalline size of hematite, while CO gas was evolved during milling, which meant the existence of the repetition of reduction and reoxidation (Figs. 11(a), $11(\mathrm{~b})$ and 11(c)). The graphite oxidation in the mixture would be the same as the one in graphite only (Figs. 11(d), 11(e) and 11(f)).

\section{Conclusions}

Milling of hematite and graphite mixture was carried out using alumina vessel and ball with planetary ball mill. Gas analysis by QMS was performed after milling. The varia-

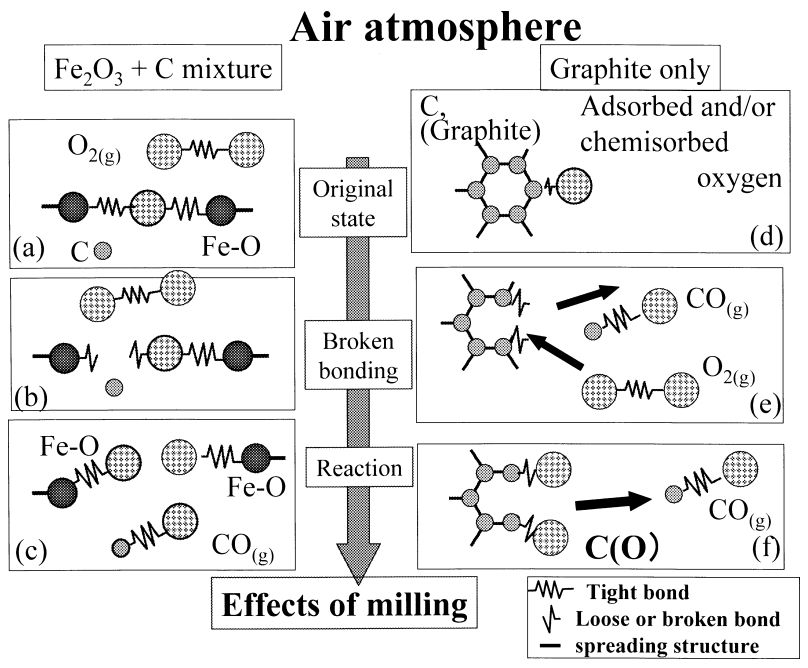

Fig. 11. Mechanism of gas evolution during the milling of the graphite only and the mixture under air atmosphere.

tion of gas evolution during milling was measured and reaction mechanism of the gas evolution was presented. Obtained results are as follows.

(1) Gas evolution from graphite was mainly $\mathrm{CO}$ gas. $\mathrm{CO}_{2}$ gas also evolved in the early stage of milling. These gases would relate to the adsorbed gases before milling. When the sample exposed to air in the course of milling, the amount of adsorption increased with the increasing milling time.

(2) When the hematite and graphite mixture was milled under argon atmosphere, mainly $\mathrm{CO}$ gas evolved owing to the reduction reaction. When the milling was carried out with 10 balls which corresponded to the lower milling energy, relatively large amount of $\mathrm{CO}_{2}$ gas evolved. In the case of 20 balls milling, the evolved gas was mainly $\mathrm{CO}$.

(3) The reaction mechanisms for the gas evolution during the milling was proposed, which corresponded to the adsorbed gases and the reduction reaction.

\section{Acknowledgement}

The present study has been carried out in the research group of 'Project for the innovational ironmaking reaction in new blast furnace at half energy consumption and minimum environmental influences' supported by Special Coordination Founds of the Science and Technology Agency of the Japanese Government. The authors would like to express great appreciation to the member of research group for the valuable discussions.

\section{REFERENCES}

1) J. Vahdati Khaki, Y. Kashiwaya, Y. Suzuki and K. Ishii: ISIJ Int., 42 (2002), 13.

2) Y. Kashiwaya and K. Ishii: ISIJ Int., 44 (2004), 1975.

3) Y. Kashiwaya Y. Suzuki and K. Ishii: ISIJ Int., 44 (2004), 1981.

4) S. Glasstone, K. J. Laidler and H. Eyring: The Theory of Rate Processes, McGraw-Hill, New York and London, (1941). 146.

5) W. J. Moore: Physical Chemistry, 4th Ed., Tokyo Kagaku Dojin, Tokyo, (1978), 387.

6) Y. Kashiwaya and K. Ishii: Tetsu-to-Hagané, 76 (1990), 1254.

7) Y. Kashiwaya and K. Ishii: ISIJ Int., 31 (1991), 440.

8) Y. Kashiwaya and K. Ishii: Tetsu-to-Hagané, 79 (1993), 1305.

9) Y. Kashiwaya and K. Ishii: Tetsu-to-Hagané, 79 (1993), 1311. 